\title{
ABSTRACT PRESENTER INDEX
}

Gary J. Kelloff, MD . . . . . . . . . . . . . . . . . 35

Carlo Maley, PhD . . . . . . . . . . . . . . . . . . . . 37

Prateek Sharma, MD . . . . . . . . . . . . . . . 37

Adam Wax, PhD ......................... 38

Gregory G. Ginsberg, MD ................. 38

Edward M. Messing, MD* .............4 41

H. Barton Grossman, MD . . . . . . . . . . . . . . 41

Mukesh Harisinghani, MD . . . . . . . . . . . . . . . . 42

Irving J. Bigio, PhD . . . . . . . . . . . . . . 42

Carol J. Fabian, MD . . . . . . . . . . . . . . . 43

Katherine Ferrara, PhD, MS . . . . . . . . . . . . . 44

Sergio Fantini, PhD . . . . . . . . . . . . . . . . . . 44

Mitchell D. Schnall, MD . .................445

Eric A. Klein, MD* . . . . . . . . . . . . . . 47

Angelo De Marzo, MD, PhD . . . . . . . . . . . . . 47

Iclal Ocak, MD ..................... 48

Jeffrey A. Ketterling, PhD . . . . . . . . . . . . . 48

Clare Tempany, MB . . . . . . . . . . . . . . . . . . . . . . 49

Daniel C. Sullivan, MD . . . . . . . . . . . . . . . . 51

Jorge Gomez, MD, PhD ................ 51

Sudhir Srivastava, MD, MPH . . . . . . . . . . . 52

Eva Szabo, MD ..................... 52

Ernest T. Hawk, MD, MPH ............... 53
Martin G. Pomper, MD, PhD . . . . . . . . . . . 55

Michael J. Birrer, MD, PhD . . . . . . . . . . . . 55

Margaret Tempero, MD* ................56

Stephen Lam, MD, FRCPC, FCCP . . . . . . . . . 57

Eric J. Seibel, PhD . . . . . . . . . . . . . . 57

Pierre Massion, MD . . . . . . . . . . . . . . . . 58

Geoffrey McLennan, MB, FRACP, PhD . . . . . . . . 58

Kevin Cleary, PhD . . . . . . . . . . . . . . . . . . . . 59

Robert Suh, MD ...................... 59

Randall W. Burt, MD . . . . . . . . . . . . . . . 61

Ruth M. Pfeiffer, PhD . . . . . . . . . . . . . . . 62

John M. Hoffman, MD . . . . . . . . . . . . . . . 62

Hemant K. Roy, MD .................... 62

Thomas Wang, MD, PhD ................ 63

Vali Papadimitrakopoulou, MD . . . . . . . . . . . 65

Walter N. Hittelman, PhD ..................66 66

Calum MacAulay, PhD . . . . . . . . . . . . . . 66

Diane Solomon, MD and Jose Jeronimo, PhD . . . . 67

Rebecca Richards-Kortum, PhD . . . . . . . . . . . 67

Steven P. Stratton, PhD . . . . . . . . . . . . . . . 69

Milind Rajadhyaksha, PhD ...............669

Atam Dhawan, PhD ...................... 70

\footnotetext{
${ }^{*}$ No abstract available for the workshop but presently included in this set.
} 